\title{
Dedicated control and measurement system for bioreactors to study the composting process
}

\author{
Krzysztof Nalepa $^{1, *}$, Maciej Neugebauer ${ }^{1}$, and Piotr Sołowiej ${ }^{1}$ \\ ${ }^{1}$ University of Warmia and Mazury in Olsztyn, Faculty of Technical Sciences, 10-719 Olsztyn, M. \\ Oczapowskiego str. 2
}

\begin{abstract}
During the composting process, waste biomass with high moisture content undergoes various transformation in the presence of oxygen. The composting process is analyzed in dedicated bioreactors which are air-tight facilities with external air supply. Subject to the type of composted plant material, biomass should be periodically turned to promote even aeration. The following information is required to build a model of the composting process: oxygen (air) uptake, moisture content of exhaust gas, production of carbon dioxide, ammonia and other gases in the composting process, and temperature distribution inside the bioreactor. A temperature monitoring system for a bioreactor is difficult to build due to challenging operating conditions including the airtight structure of a bioreactor, high moisture content, the operation of temperature sensors in a highly aggressive environment, problems with uninterrupted power supply for the monitoring system in a bioreactor. This article presents a patented temperature monitoring system for a bioreactor. The system's design and structure are discussed, and recommendations for functional improvements are made.
\end{abstract}

\section{Introduction}

Composting, a natural process of converting biological waste into a useful product compost, has been known to man for ages [1]. At present, the management of highly differentiated types of waste, which were not encountered in the previous centuries, poses a considerable problem. An example can be sewage sludge and large amounts of agricultural and food processing waste $[2,3]$. These types of waste are difficult to compost due to their quantity, structure, bacterial contamination and other factors $[4,5]$. Therefore, the optimal parameters of the composting process have be determined experimentally to ensure that different types waste are effectively decomposed and sanitized [6, 7].

The following parameters play an important role during the composting process: aeration rate, gas production ( $\mathrm{CO} 2$, odorous gases such as $\mathrm{NH} 3)$, composting temperature (to guarantee safe sanitation of the produced compost), changes in the moisture content of the composted material, and the $\mathrm{C} / \mathrm{N}$ ratio $[8,9]$

\footnotetext{
*Corresponding author: naklepka@uwm.edu.pl
} 
The composting process should be optimized to ensure that different types of decomposed waste (or mixtures of waste material) are effectively converted into compost that can be safely used as natural fertilizer (free of pathogens, bacteria and heavy metals), while minimizing the emission of odorous gases $[10,11]$. The decomposition of various types of waste has to be examined at different stages of composting to optimize process parameters at the planning stage. Such analyses are conducted in dedicated bioreactors [12]. The quality of the produced compost as well as the parameters of the composting process have to be investigated. The resulting knowledge is used to develop the optimal models for composting selected types of biological waste, to ensure that biological waste is fully sanitized, or to shorten composting time and maximize the performance of industrial equipment [13]. The following composting parameters are measured in a bioreactor: temperature, moisture content, aeration rate, and concentration of gases in exhaust air [14].

The temperature and moisture content of composted substrate are the key parameters of the composting process, but they are difficult to measure. These parameters should be monitored continuously (without opening the bioreactor if possible) at several points in the fermentation chamber [15]. The processes that occur inside a bioreactor are highly aggressive (high moisture content, temperature fluctuations and corrosive $\mathrm{pH}$ ), and most sensors are rapidly damaged. The optimal measuring probe should enable simultaneous measurements of temperature at several points, it should operate independently of external power supply, and it should support full data recording.

The structure and operating principles of a temperature probe that meets the above criteria are described in this study. The probe supports fully automated temperature measurements inside an air-tight bioreactor (the bioreactor does not have to be opened during measurements), and it contributes to the integrity of measured temperature data.

\section{Structure of the monitoring system}

The system for monitoring temperature inside the fermentation chamber was divided into several functional subunits. A block diagram of the designed system is presented in Figure 1. The experimental setup was limited to measuring probes that can operate in the aggressive environment of the bioreactor chamber and are resistant to malfunctions and system failure. The probes provide accurate and reliable information about temperature changes during the composting process that lasts several to several dozen days.

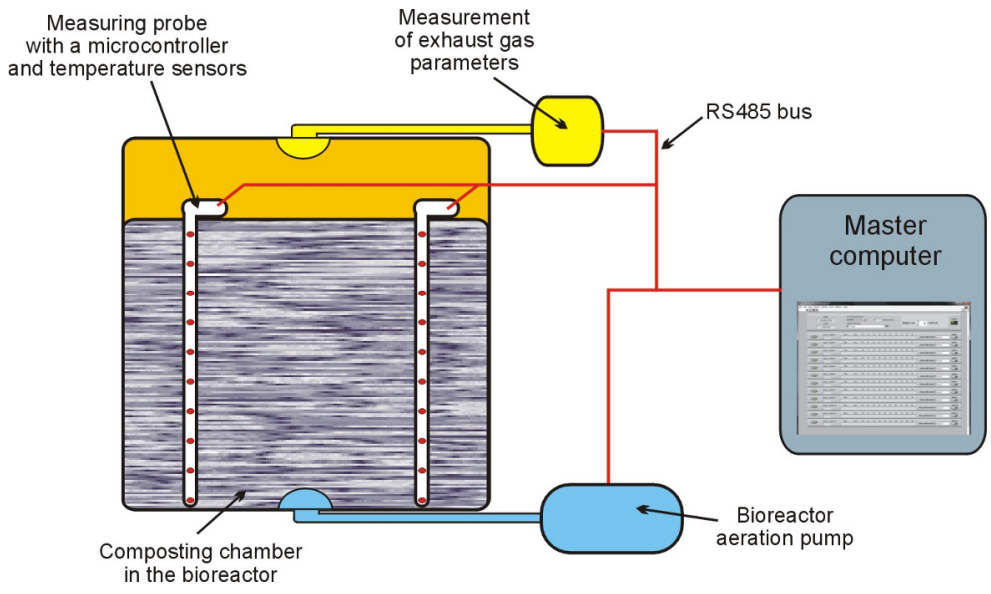

Fig. 1. Block diagram of a dedicated system for monitoring temperature changes in the composting chamber. Source: own elaboration. 
The main functional subunit in the designed system is composed of sensors which measure the distribution of temperature inside the composed substrate. The probe set, hereinafter referred to as the Measuring Probe (Fig. 2), contains 10 Dallas - DS18B20 digital temperature sensors connected to the Atmel Mega328P single-chip microcontroller. The microcontroller communicates with the master computer, controls the operation of temperature sensors, reads data from sensors, aggregates packets of measured data for the system's communication network, and transmits data to the master computer upon request. The communication between the components of the monitoring system is based on the RS485 standard.

1-Wire bus

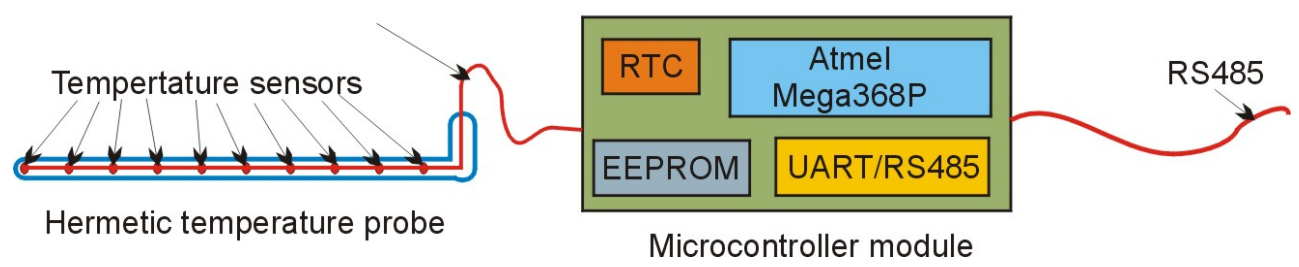

Fig. 2. Flowchart of a measuring probe. Source: own elaboration.

Every measuring probe can also be operated as an independent monitoring system outside the system's control. In this case, the measured data are recorded in $512 \mathrm{~kb}$ EEPROM memory. This mode of operation is selected in two cases. In the first case, the measuring probe operates as an independent monitoring system when measurements have to be performed remotely from the main monitoring system. Data stored in EEPROM memory can be read by a dedicated program module in the master computer. In the second case, the measuring probe is activated during a failure of the communication network in the monitoring system. In this case, the measuring probe switches to independent operation mode, data are stored in EEPROM memory and can be read via a dedicated program module connected to the master computer. In this mode, data are read continuously even in the event of failure of the master computer or the system's communications network.

The monitoring system is controlled by a dedicated program developed in the LabView environment. Several functional program modules have been developed. The main module is responsible for the measurements conducted by all probes connected to the system (Figure 3). Temperature data read by the measuring probes are saved in text files. A probe is activated and data are saved in files with the use of controls (buttons) in the developed program. The experimental setup can work with up to 12 measuring probes.

Two additional program modules have been designed to configure the operating parameters of measuring probes, including a real-time clock and the interval between measurements in the independent mode. The second module reads the data stored in EEPROM memory.

A window in the LabView program where the user can activate each temperature sensor connected to the system and read the temperatures registered by each measuring probe is presented in Figure 4. 


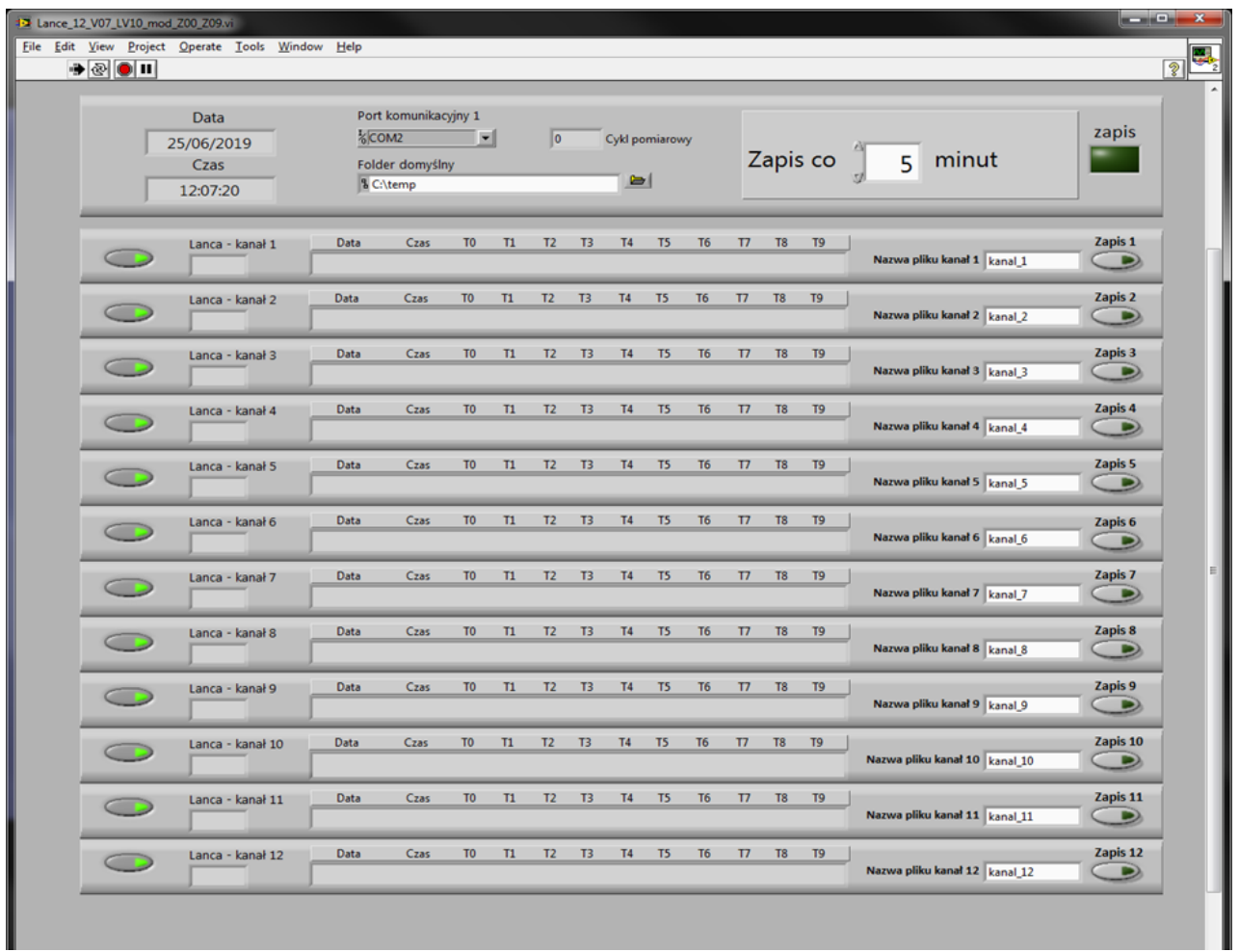

Fig. 3. Main window in the program for reading, presenting and saving data from measuring probes. Source: own elaboration.

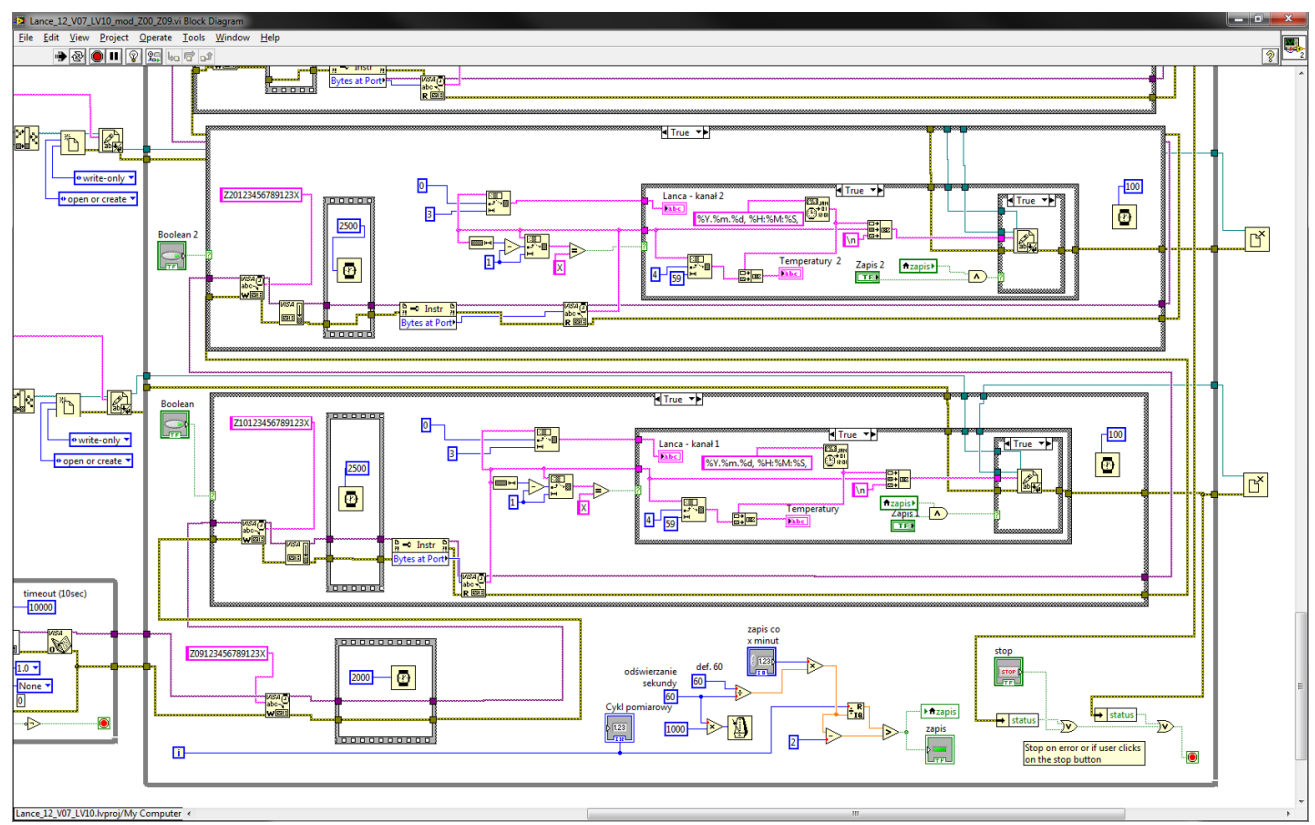

Fig. 4. A window in the LabView program for reading, presenting and recording data. Source: own elaboration. 


\section{Conclusions}

The presented measuring system enabled effective monitoring of the parameters of the composting process inside a bioreactor.

The designed system, where the measuring probe is composed of 10 evenly distributed temperature sensors and where more than one measuring probe can be placed inside the bioreactor chamber, delivers reliable information about spatial temperature distribution during the composting process in a bioreactor.

The use of measuring probes equipped with independent real-time clocks and EEPROM memory for storing the data from temperature sensors connected to the microcontroller of each measuring probe guarantees uninterrupted operation of the monitoring system during the failure or malfunction of different system components, such as the communication bus.

\section{References}

1. R.R. Cardenas, L.K. Wang, Composting Process. In: L.K.Wang, N.C. Pereira (eds), Solid Waste Processing and Resource Recovery. Handbook of Environmental Engineering, vol 2. Humana Press (1980).

2. J. Yuan, D. Chadwick, D. Zhang, G. Li, S. Chen, W. Luo, L. Du, S. He, S. Peng, Waste Management, 56, 403-410 (2016).

3. D. Kulikowska, Waste Management, 49, 196-203 (2016).

4. L.R.D. Sommaggio, D.E.C. Mazzeo, D. de Andrade e Silva Sant' Anna, C.E. Levy, M.A. Marin-Morales, Ecotoxicology and Environmental Safety, 147, 550-557 (2018).

5. L. Zhang, X. Sun, Waste Management, 48, 115-126 (2016).

6. R. Rentería-Tamayo, G. Vidriales-Escobar, O. González-Ortega, et al., Waste Biomass Valorization (2018).

7. W. Liu, R. Huo, J. Xu, S. Liang, J. Li, T. Zhao, S. Wang, Bioresource Technology, 235, 43-49 (2017).

8. A. Cerda, A. Artola, X. Font, R. Barrena, T. Gea, A. Sánchez, Bioresource Technology, 248, Part A, 57-67 (2018).

9. M. Neugebauer, Journal of Environmental Management, 225, 133-138 (2018).

10. W. Czekała, J. Dach, R. Dong, D. Janczak, K. Malińska, K. Jóźwiakowski, A. Smurzyńska, M. Cieślik, Biosystems Engineering, 160, 25-29 (2017).

11. D. Janczak, K. Malińska, W. Czekała, R. Cáceres, A. Lewicki, J. Dach, Waste Management, 66, 36-45 (2017).

12. W. Czekała, J. Dach, K. Malińska, J. Przybył, M. Myszura, Journal of Ecological Engineering, 16 3, 108-114 (2015).

13. P. Proietti, R. Calisti, G. Gigliotti, L. Nasini, L. Regni, A. Marchini, Journal of Cleaner Production, 137, 1086-1099 (2016).

14. A. Sánchez A. et al. Greenhouse Gas from Organic Waste Composting: Emissions and Measurement. In: Lichtfouse E., Schwarzbauer J., Robert D. (eds) CO2 Sequestration, Biofuels and Depollution. Environmental Chemistry for a Sustainable World, 5, (2015).

15. K. Nakasaki, H. Hirai, Waste Management, 65, 29-36 (2017). 